\title{
Survey Data Analysis on Intention to Use Shared Mobility Services
}

\author{
Eunjeong Ko, ${ }^{1}$ Hyungjoo Kim, ${ }^{2}$ and Jinwoo Lee $\mathbb{D}^{1}$ \\ ${ }^{1}$ The Cho Chun Shik Graduate School of Green Transportation, Korea Advanced Institute of Science and Technology, \\ Daejeon 34051, Republic of Korea \\ ${ }^{2}$ Advanced Institute of Convergence Technology, Changeop-ro 42, Sujeong-gu, Seongnam, Gyeonggi-do 13449, Republic of Korea \\ Correspondence should be addressed to Jinwoo Lee; lee.jinwoo@kaist.ac.kr
}

Received 5 February 2021; Revised 6 March 2021; Accepted 22 March 2021; Published 7 April 2021

Academic Editor: Zhibin Li

Copyright (c) 2021 Eunjeong Ko et al. This is an open access article distributed under the Creative Commons Attribution License, which permits unrestricted use, distribution, and reproduction in any medium, provided the original work is properly cited.

\begin{abstract}
Shared mobility is a service that allows users to share various transportation modes and use them with reservations when necessary. It started with private automotive car-sharing and ride-sharing services. Currently, it operates on a wider range, including personal mobility devices such as electric bicycles and scooters. The purpose of this study is to derive a direction for providing future shared mobility services through analysis of factors affecting the usage intention of both current and prospective users. The survey targets 753 citizens living in Gyeonggi Province, Korea. The survey period is from February 12, 2020, to February 26,2020 . In this study, a logistic regression analysis is conducted to investigate the factors affecting the use intention of shared mobility. The analysis results show that gender, car ownership, and education, among variables reflecting socio-demographic characteristics, have significant effects on intention to use shared mobility. Moreover, we find that experience factors, including mainly used transportation modes, ownership of shared mobility device, past experience in similar services, satisfaction of existing shared mobility services, and distance from the home to the nearest bus stop, are also statistically influential. The analysis results are expected to lay the foundation for the introduction of shared mobility services and can be used as data for planning smart mobility services in the future.
\end{abstract}

\section{Introduction}

As negative impacts of autoownership have gradually increased, such as significant energy consumption, traffic congestion, inefficient land use, and excessive vehicle purchasing and operating costs, drivers have begun to look for alternatives [1]. Accordingly, shared mobility, a service that allows users to share various transportation modes and use them when necessary [2], has emerged as a major solution to existing transportation problems $[1,3-5]$. This can be further divided into conventional automotive vehicle-sharing and personal mobility-sharing services in terms of types of vehicles to share [6]. The former involves car-sharing and ride-sharing services [7]: car sharing is when people share vehicles instead of using private vehicles (e.g., Drivy and Zipcar), often associated with a subscription fee, and ride sharing is when multiple passengers share their routes either partially or completely by a single vehicle (e.g., BlaBlaCar and Via).
Car sharing was introduced in Zurich, Germany, in 1948, as a car rental service, but it did not gain much popularity until in the late 1980s [1]. Besides this, personal mobility-sharing services were first introduced in Amsterdam, the Netherlands, in 1965, in a system that allowed people to share public bicycles; however, it was difficult to proceed with long-term planning as a result of bicycle damage or theft issues [8]. However, demand for alternative mobility has been continuously increasing according to its advantages (e.g., low cost, autonomy, flexibility, and rental in recent years) [9] and the disadvantages of owning personal cars (e.g., increased urban problems and uncertainty in future operation expenses) [1].

In recent years, with the successful introduction of shared mobility service in Europe thanks to advancements in telecommunication systems, many related studies have been carried out from different perspectives such as infrastructure planning for car-sharing and bicycle-sharing services $[10,11]$, estimation of benefits and impacts [12-16], social 
norms [17-19], infrastructure resiliency and influence of social networks [20-22], and user demand and characteristics analysis [23-25].

Especially, analysis of the user's intentions is attracting much attention in which it is closely related to future demand forecasting and economic evaluation. For example, Simsekoglu and Klöckner analyzed psychological attitudes and social determinants of electric bicycle use through structural equation modeling analysis [23]. Matyas and Kamargianni used a stated preference survey method to obtain initial insight into whether sharing modes can be used as a successful or feasible mobility tool [24]. Most recently, Ho et al. investigated user preferences for shared mobility. They identified the impact of current on-demand mobility services and obtained insight from customer demand analysis in terms of socio-economic conditions and travel needs [25]. However, such studies of user intention still have limitations in which they usually focused on a single specific shared mobility mode.

While the spread of shared mobility has increased, most user-related studies have analyzed factors influencing the use of shared transportation modes that are already widely used. In the analysis based on the shared mobility services already implemented, there is a possibility that established services did not fully reflect future user intention in the planning stages. Thus, such post-hoc analyses can be biased in terms of what potential users actually want and need, varying according to their individual situations. Thus, to predict the correct direction of the provision of a service based on the exact needs of users, it is necessary to analyze the intention to use a shared mobility system that has not been implemented yet.

To fill this research gap, we have conducted an online survey for citizens living in Gyeonggi Province, Korea, and carried out an ex-ante analysis of intention to use types of shared mobility services through a logistic regression model. The intended contributions of this study can be summarized threefold:

(1) We conduct an ex-ante analysis of potential user needs for shared mobility services to overcome the biases possibly inherent in the previous post-hoc analyses

(2) We identify factors that influence user needs based on their statistical significance and quantify the extent of influence using survey data collected from Gyeonggi Province, Korea

(3) We qualitatively suggest the direction of provision of shared mobility service in consideration of potential users' intention

The following section describes the questionnaire and sample characteristics used in this study. In addition, this section shows the statistics of the current usage status of various transportation modes. Section 2 presents the statistical method used to analyze the collected data. The results are documented Section 3. Section 4 summarizes the findings and suggests policy directions to enhance the effectiveness and efficiency of shared mobility plans for the future.

\section{Data Description}

2.1. Survey Overview and Questionnaire Design. An online survey has been conducted to analyze the characteristics and factors affecting the potential user's intention of shared mobility services. It targets people aged from 19 to 65 who live in Gyeonggi Province, Korea, and its survey period is from February 12, 2020, to February 26, 2020. This province is characterized by dense traffic zones that are satellite cities connected to Seoul City, the capital of Korea. Each of the province and the capital city is home to more than 10 million people, and there are a large number of people commuting to Seoul City from the surrounding satellite cities. While 781 responses were collected, we select a total of 753 samples due to the incompleteness of responses [26, 27]. In detail, samples are excluded in the following cases: (i) if there is no response to a question that needs to be answered and (ii) if multiple responses are made to a question that requires one answer.

The survey is comprised of three parts. The first part is a respondent socio-demographic characteristic (e.g., gender, age, job, household size, household income, and residential area) [28]. The second part is about the current and recent past use of conventional transportation modes and existing shared mobility services in the province. Specifically, the survey provides a detailed description of the shared mobility services (Table 1) and asks if the respondents are currently using or have used them and how satisfied they are to understand how their past experiences affect the future intention. The reason we consider only the past month's experiences is twofold. First, conventional transportation modes are mainly for commuting. Thus, the one-month survey can reflect the actual usage patterns. Second, the shared mobility services and their penetration rates are rapidly changing and still at a pilot phase, so the current perception of shared mobility services could not be highly influenced by old experiences obtained when the service environments were different from now. Since satisfaction is difficult to observe and measure explicitly, it is collected using the Likert scale $[28,29]$. The third part is a future preference survey assuming that shared mobility services will be provided. The survey questionnaire is summarized in Table 2 .

2.2. Sample Characteristics. An analysis of respondent characteristics confirms that the composition of the respondents reflects the entire socio-demographic characteristics of commuters in Korea. The sample numbers for different gender are almost even. Moreover, all age groups except for the 60 s have almost the same sample number. As for the job, full-time workers occupy the majority of the respondents, so the collected sample reflects commuter traffic well [9]. Table 3 shows the statistical characteristics of the collected samples.

2.3. Usage Status of Transportation Modes and Shared Mobility Services. We survey the usage status of conventional transportation modes and shared mobility services, focusing on the experiences of respondents. We focus on the frequently used transportation modes in the past month of each 
TABLE 1: Description of the shared mobility services.

\begin{tabular}{lll}
\hline Service & Concept & How to use
\end{tabular}

(1) Search for nearby parking lot using the smartphone app

Car sharing $\quad$ A short-term rental service for members

(2) Select and reserve a vehicle (3) Park in the parking lot after use

Ride sharing A service that pays for and boards privately owned vehicles during rush hours
(1) Enter departure point, boarding time, and destination using the smartphone app

(2) Take the vehicle and use it

(1) Search for nearby electric bicycle or scooter using the smartphone app

Personal mobility A sharing service for single-person transportation modes sharing powered by electric batteries

(2) Select and reserve an electric bicycle or scooter

(3) Park freely after use

TABLE 2: Summary of survey questionnaire.

\begin{tabular}{lc}
\hline Part & \begin{tabular}{c} 
Variables description \\
\hline Part $1>$
\end{tabular} \\
$\begin{array}{l}\text { Sample socio-demographic factors } \\
<\text { Part } 2>\end{array}$ & $\begin{array}{c}\text { Gender, age, job, education, household size, household income, } \\
\text { residence, etc. }\end{array}$ \\
$\begin{array}{l}\text { Usage status and experiences of transportation and shared mobility } \\
\text { service }\end{array}$ & $\begin{array}{c}\text { Usage status of transportation in the past month } \\
\text { Usage status of shared mobility service in the past month }\end{array}$ \\
$\begin{array}{l}<\text { Part } 3> \\
\text { Preference of shared mobility service }\end{array}$ & Intention to use the shared mobility \\
\hline
\end{tabular}

TABle 3: Characteristics of the respondents.

\begin{tabular}{|c|c|c|c|}
\hline \multicolumn{2}{|c|}{ Sample attributes } & \multirow{2}{*}{$\begin{array}{c}\text { Number of the samples } \\
438\end{array}$} & \multirow{3}{*}{$\begin{array}{c}\% \\
58.2 \\
41.8\end{array}$} \\
\hline & Male & & \\
\hline Gender & Female & 315 & \\
\hline \multirow{5}{*}{ Age } & 20 's & 169 & 22.4 \\
\hline & 30 's & 174 & 23.1 \\
\hline & 40 's & 176 & 23.4 \\
\hline & 50 's & 146 & 19.4 \\
\hline & 60 's & 88 & 11.7 \\
\hline \multirow{6}{*}{ Job } & Professional/technical worker & 156 & 20.7 \\
\hline & Administrative/office worker & 381 & 50.6 \\
\hline & Service worker & 56 & 7.4 \\
\hline & Production worker & 38 & 5.0 \\
\hline & Self-employed worker & 76 & 10.2 \\
\hline & Student & 46 & 6.1 \\
\hline \multirow{2}{*}{ Education } & High school & 87 & 11.6 \\
\hline & University or higher & 666 & 88.4 \\
\hline \multirow{5}{*}{ Household size } & 1 & 100 & 13.3 \\
\hline & 2 & 119 & 15.8 \\
\hline & 3 & 208 & 27.6 \\
\hline & 4 & 265 & 35.2 \\
\hline & 5 and above & 61 & 8.1 \\
\hline \multirow{6}{*}{ Household income } & Under 2,000,000 KRW* & 53 & 7.0 \\
\hline & 2,000,000 2,999,999 KRW & 129 & 17.1 \\
\hline & 3,000000 4,999,999 KRW & 242 & 32.1 \\
\hline & $5,000,000 \sim 6,999,999 \mathrm{KRW}$ & 176 & 23.4 \\
\hline & 7,000,000 9,999,999 KRW & 106 & 14.1 \\
\hline & $10,000,000 \mathrm{KRW}$ and above & 47 & 6.2 \\
\hline \multirow{4}{*}{ Population } & 600,000 and above & 290 & 38.5 \\
\hline & $300,000 \sim 599,999$ & 197 & 26.2 \\
\hline & Under 300,000 & 220 & 29.2 \\
\hline & County area & 46 & 6.1 \\
\hline
\end{tabular}

\footnotetext{
* denotes South Korean won.
} 
respondent. Driving an owned vehicle is the most common mobility mode, followed by using conventional public transit such as subways, buses, and railroads. KTX presented in Table 4 is an abbreviation of the "Korea Train express" operated by Korail, a Korean railway company. The use of car-sharing and shared personal mobility services occupies around $1 \%$, much lower than that of other conventional transportation modes. Thus, it means that this study focuses on people's intentions who live in cities where shared mobility is not prevailing. In Table 4, the vehicle-sharing system, so-called macromobility, includes car sharing and ride sharing, and the personal mobility-sharing system, a component of micromobility, involves electric bicycle and scooter sharing.

We analyze the usage status and characteristics of respondents who have experienced shared mobility services more than once, which are documented in Tables 5 and 6, respectively. The results show car sharing has the highest number of once-experienced users, followed by shared electric bicycle, ride sharing, and shared electric scooter. For the purpose of usage, leisure/tourism has the highest proportion for each type of service, but the total usage for commuting is relatively low [30]. Furthermore, as can be intuitively expected, the travel distance and time per usage are longer in car sharing and ride sharing than personal mobility modes.

2.4. Analysis Method. Linear regression analysis reveals the correlation between one dependent variable and multiple independent variables if we assume that the dependent variable changes linearly by independent variables [31]. However, it is not suitable for dealing with binomial or discrete events. In contrast, logistic regression can analyze the nonlinear relationship between the dependent variable and independent variables that are binary or discrete. Therefore, it has the advantage of being able to understand the relationship between the binary dependent variable and several independent variables affecting various shared mobility choices [31]. For a shared mobility service, the willingness-to-use of a potential user, denoted by $p$, is mathematically expressed as equation (1). It is obviously a nonlinear function of $n$ potentially influential factors indexed by $i, x_{1}, \ldots, x_{n}$, coupled with their coefficients, $\beta_{0}, \beta_{1}, \ldots \beta_{n}$. Even if the expression of $p$ is nonlinear, the estimation of the coefficients can be efficiently done by transforming it to a linear form. The odds of $p$ is $p /(1-p)$, and the logarithm of it is defined as the logit of $p, \operatorname{Logit}(p)$. As shown in equation (2), Logit $(p)$ is a linear function of the inputs, so we can apply a linear regression to estimate the coefficients, $\beta_{0}, \beta_{1}, \ldots \beta_{n}$. In this paper, SPSS Statistics 25.0 software is used for the calculation:

$$
\begin{gathered}
p=\frac{e^{\left(\beta_{0}+\sum \beta_{i} x_{i}\right)}}{1+e^{\left(\beta_{0}+\sum \beta_{i} x_{i}\right)}}, \\
\operatorname{Logit}(p)=\log \frac{p}{1-p}=\beta_{0}+\beta_{1} x_{1}+\beta_{2} x_{2}+\cdots+\beta_{i} x_{i} .
\end{gathered}
$$

TABLE 4: Usage status of transportation as the primary mode.

\begin{tabular}{lcc}
\hline Transportation modes & Number of the samples & $\%$ \\
\hline Privately owned vehicle & 333 & 44.2 \\
Subway & 193 & 25.6 \\
City bus & 134 & 17.8 \\
Intercity bus & 52 & 6.9 \\
Shuttle bus & 16 & 2.1 \\
On foot & 5 & 0.7 \\
KTX & 3 & 0.4 \\
Vehicle-sharing system & 9 & 1.2 \\
Personal mobility-sharing system & 8 & 1.1 \\
\hline
\end{tabular}

In this study, the collected data about socio-demographic characteristics and past transportation usage statistics are considered as potential influential factors $\left(x_{1}, \ldots, x_{n}\right)$. The user intention of using a shared mobility is set as a dependent variable $(p)$. Table 7 shows the input types of variables used in the model.

The detailed description of each variable is as follows: gender is divided into male and female; mainly, used transportation means whether you primarily use a vehicle or transportation when commuting; car ownership means you possess a vehicle that you can drive freely; ownership of shareable vehicle means respondents have at least one extra private vehicle that can be shared with other users; ownership of personal mobility device means respondents have electric bicycle or scooter; the education level is divided into twofold: high-school graduation and university or higher; previous experience refers to whether respondents have been used vehicle-sharing or personal mobility-sharing services; age is as natural number variables; distance from home to the nearest bus stop is as continuous variables in kilometers; satisfaction is measured on 5-point scale to show how satisfied the respondents were when they used the existing shared mobility services.

To identify variables associated with a significant correlation, we perform Pearson's correlation analysis. Furthermore, a multicollinearity test has been conducted to check if the selected variables are free from multicollinearity with other variables. The analysis results through the correlation and the multicollinearity analysis are presented in Figure 1 and Table 8, respectively.

The titles of the rows and columns in Figure 1 means the following. Transportation is mainly used transportation; Car refers to car ownership; SV means ownership of sharable vehicle; PMD indicates ownership of personal mobility device; PEVS denotes previous experience in vehicle sharing; PEPMS represents previous experience in mobility-sharing; Distance stands for distance from home to bus stop.

Figure 1 shows the results of extracting significant variables related to user intention. In this figure, the overall result has a weak correlation, as the correlation is lower than or equal to 0.3 [32]. A few variables exceed 0.3 , but we can consider them as moderate correlations since they are below 0.7 [32]. 
TABLE 5: Usage status of shared mobility services.

\begin{tabular}{|c|c|c|c|c|}
\hline Sample attributes & & & Number of the samples & $\%$ \\
\hline \multirow{8}{*}{ Usage } & \multirow{2}{*}{ Car sharing } & Yes & 117 & 23.5 \\
\hline & & No & 576 & 76.5 \\
\hline & \multirow{2}{*}{ Ride sharing } & Yes & 72 & 9.6 \\
\hline & & No & 681 & 90.4 \\
\hline & \multirow{2}{*}{ Shared electric bicycle } & Yes & 139 & 18.5 \\
\hline & & No & 614 & 81.5 \\
\hline & \multirow{2}{*}{ Shared electric scooter } & Yes & 55 & 7.3 \\
\hline & & No & 698 & 92.7 \\
\hline \multirow{15}{*}{ Purpose of usage } & \multirow{4}{*}{ Car sharing } & Commuting & 42 & 23.7 \\
\hline & & Business & 34 & 19.2 \\
\hline & & Leisure/tourism & 98 & 55.4 \\
\hline & & Others & 3 & 1.7 \\
\hline & \multirow{3}{*}{ Ride sharing } & Commuting & 20 & 27.8 \\
\hline & & Business & 17 & 23.6 \\
\hline & & Leisure/tourism & 35 & 48.6 \\
\hline & \multirow{4}{*}{ Shared electric bicycle } & Commuting & 37 & 26.6 \\
\hline & & Business & 17 & 12.2 \\
\hline & & Leisure/tourism & 84 & 60.4 \\
\hline & & Others & 1 & 0.7 \\
\hline & \multirow{4}{*}{ Shared electric scooter } & Commuting & 14 & 25.5 \\
\hline & & Business & 15 & 27.3 \\
\hline & & Leisure/tourism & 23 & 41.8 \\
\hline & & Others & 3 & 5.5 \\
\hline
\end{tabular}

TABLE 6: Usage characteristics of shared mobility services.

\begin{tabular}{lccc}
\hline Sample attributes & Average number of use & Distance per use $(\mathrm{km})$ & Time \\
\hline Car sharing & 3.4 & 38.9 & 101.5 \\
Ride sharing & 3.2 & 16.3 & 34.4 \\
Shared electric bicycle & 3.2 & 10.6 & 38.4 \\
Shared electric scooter & 4.1 & 13.7 & 30.9 \\
\hline
\end{tabular}

TABLE 7: Variable format of the estimation model.

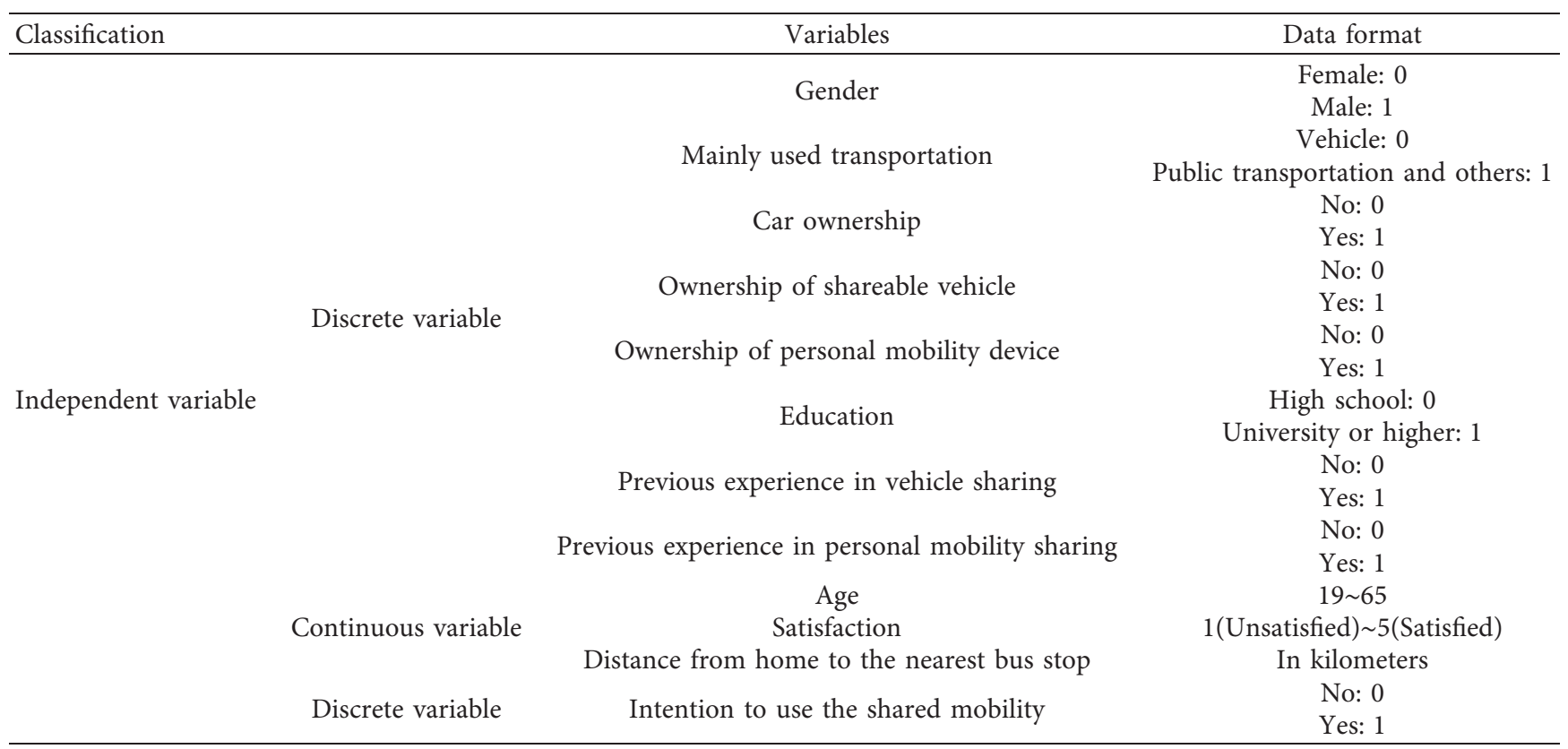




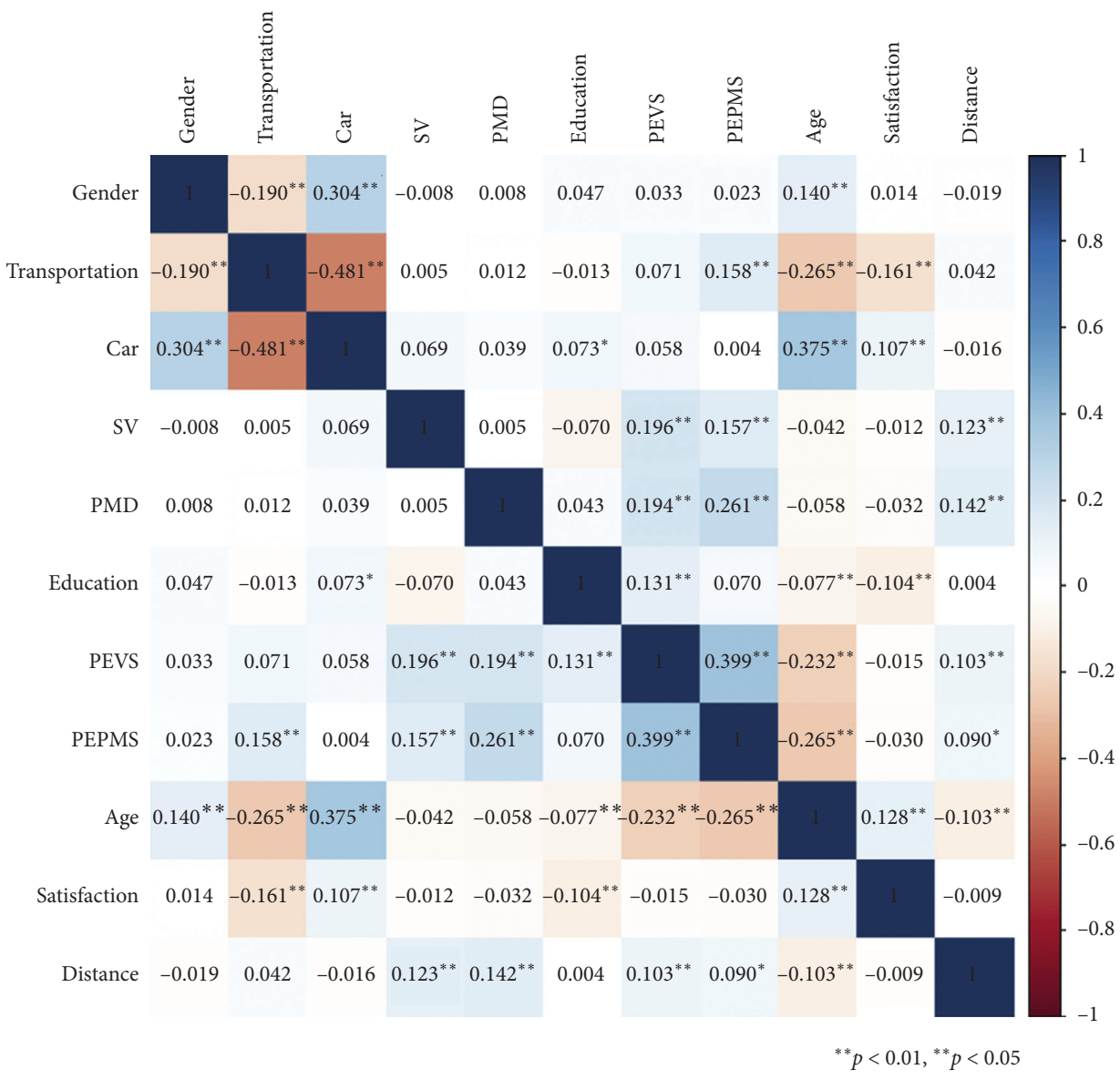

Figure 1: Result of correlation.

For the variables with high significance shown in Figure 1, their VIF values are derived as shown in Table 8. VIF is a measure that calculates the association between a fixed independent variable and the other independent variables. If the VIF of a certain variable is 10 or more, we can understand that multicollinearity exists with the variable. Moreover, if this value exceeds 5, it is considered that attention is needed. In this case, it is inappropriate to put it into the model because the highly correlated variables can affect the model and result in undesirable biases [33]. As a result of the analysis, all estimated VIF values are lower than 5 , so we find that multicollinearity does not exist.

A detailed description of each notation is in Table 1. $B$ is a predicted value, meaning influence of the variable and Beta is the standardized value of $B$; S.E is the standard error, which estimates the variability; $t$ is a value that is the difference between the predicted value divided by standard error, which compares the differences according to variability; Sig. judges whether it is valid within the significance level (95\% confidence level in this study); allowance and variance inflation factor (VIF) are indicators of multicollinearity.

In general, the model is evaluated using $R^{2}$ of Cox and Snell and $R^{2}$ of Nagelkerke in regression analysis. However, for logistic regression, $R^{2}$ is generally low and depends on the dependent variable, so it is not appropriate to evaluate the adequacy of model $[34,35]$. Thus, Hosmer and Lemeshow test, which is a goodness-of-fit method that performs a verification of the degree of agreement between a predicted value and an observed value using a chi-square distribution [34], is used to test the fit of the proposed model. If the results are greater than the set significance level, it can describe that the model is well estimated.

We set the final estimation model using the variables that are selected by using the backward elimination method, which has been known to be appropriate to prevent removing statistically meaningful variables related to the dependent variable compared to the alternative, the forward elimination method [36]. Table 9 shows the description and detailed verification results of the model through the Hosmer and Lemeshow test. The chi-square measure is estimated as 8.718 , and the significance level is 0.367 , which is greater than the standard, 0.05. Thus, the estimated model is statistically suitable to represent intention to use shared mobility services.

\section{Discussion}

Table 10 describes the model estimation results. The detailed description of notation is as follows: Wald means how important a variable is to describe a model; d.f is the degree 
TABLE 8: Result of multicollinearity.

\begin{tabular}{|c|c|c|c|c|c|c|c|}
\hline \multirow[t]{2}{*}{ Variables } & \multicolumn{2}{|c|}{$\begin{array}{l}\text { Nonstandard } \\
\text { coefficient }\end{array}$} & \multirow{2}{*}{$\begin{array}{c}\text { Standard coefficient } \\
\text { Beta }\end{array}$} & \multirow[t]{2}{*}{$\mathrm{t}$} & \multirow[t]{2}{*}{ Sig. } & \multicolumn{2}{|c|}{ Collinearity value } \\
\hline & $\mathrm{B}$ & S.E & & & & Allowance & VIF \\
\hline Constant & -0.121 & 0.111 & & 1.082 & 0.280 & & \\
\hline Gender & 0.074 & 0.036 & 0.075 & 2.080 & 0.038 & 0.900 & 1.111 \\
\hline Mainly used transportation & 0.097 & 0.039 & 0.099 & 2.462 & 0.014 & 0.727 & 1.376 \\
\hline Car ownership & 0.103 & 0.048 & 0.091 & 2.129 & 0.034 & 0.631 & 1.584 \\
\hline Ownership of shareable vehicle & 0.124 & 0.050 & 0.088 & 2.468 & 0.014 & 0.924 & 1.082 \\
\hline Ownership of personal mobility device & 0.144 & 0.061 & 0.085 & 2.356 & 0.019 & 0.902 & 1.108 \\
\hline Education & 0.131 & 0.054 & 0.085 & 2.431 & 0.015 & 0.950 & 1.053 \\
\hline Previous experience in vehicle sharing & 0.107 & 0.042 & 0.097 & 2.510 & 0.012 & 0.774 & 1.293 \\
\hline Previous experience in personal mobility sharing & 0.213 & 0.048 & 0.176 & 4.456 & 0.0001 & 0.750 & 1.334 \\
\hline Age & 0.002 & 0.002 & 0.045 & 1.134 & 0.257 & 0.747 & 1.339 \\
\hline Satisfaction & 0.016 & 0.017 & 0.032 & 0.927 & 0.354 & 0.953 & 1.050 \\
\hline Distance from home to the nearest bus stop & 0.014 & 0.006 & 0.082 & 2.345 & 0.019 & 0.955 & 1.047 \\
\hline
\end{tabular}

Table 9: Model verification.

\begin{tabular}{lcr}
\hline Variables & & Value \\
\hline Model summary & Cox and Snell $R^{2}$ & 0.162 \\
& Nagelkerke $R^{2}$ & 0.219 \\
\hline & $x^{2}$ & 8.718 \\
Hosmer and Lemeshow test & Degree of freedom & 8 \\
& Significance & 0.367 \\
\hline
\end{tabular}

TABle 10: Model estimation.

\begin{tabular}{|c|c|c|c|c|c|c|c|c|}
\hline \multirow[t]{2}{*}{ Variable } & \multirow[t]{2}{*}{$\mathrm{B}$} & \multirow[t]{2}{*}{ S.E } & \multirow[t]{2}{*}{ Wald } & \multirow[t]{2}{*}{ d.f } & \multirow[t]{2}{*}{ Sig. } & \multirow[t]{2}{*}{$\operatorname{Exp}(B)$} & \multicolumn{2}{|c|}{$\begin{array}{l}95 \% \text { C.I for } \\
\exp (\mathrm{B})\end{array}$} \\
\hline & & & & & & & Lower & Upper \\
\hline Constant & -0.643 & 0.430 & 2.235 & 1 & 0.135 & 0.526 & & \\
\hline Gender & 0.377 & 0.173 & 4.750 & 1 & 0.029 & 0.686 & 0.489 & 0.963 \\
\hline Mainly used transportation & 0.514 & 0.196 & 6.883 & 1 & 0.009 & 1.671 & 1.139 & 2.453 \\
\hline Car ownership & 0.589 & 0.224 & 6.925 & 1 & 0.008 & 1.802 & 1.162 & 2.794 \\
\hline Ownership of shareable vehicle & 0.738 & 0.272 & 7.363 & 1 & 0.007 & 2.091 & 1.227 & 3.564 \\
\hline Ownership of personal mobility device & 1.000 & 0.381 & 6.902 & 1 & 0.009 & 2.719 & 1.289 & 5.735 \\
\hline Education & 0.608 & 0.258 & 5.541 & 1 & 0.019 & 1.837 & 1.107 & 3.048 \\
\hline Previous experience in vehicle sharing & 0.468 & 0.212 & 4.884 & 1 & 0.027 & 1.598 & 1.054 & 2.421 \\
\hline Previous experience in personal mobility sharing & 1.179 & 0.269 & 19.284 & 1 & 0.0003 & 3.252 & 1.921 & 5.504 \\
\hline Satisfaction & & & 16.320 & 4 & 0.003 & & & \\
\hline Satisfaction (1) & -0.640 & 0.472 & 1.840 & 1 & 0.175 & 0.527 & 0.209 & 1.329 \\
\hline Satisfaction (2) & -0.323 & 0.364 & 0.786 & 1 & 0.375 & 0.724 & 0.354 & 1.479 \\
\hline Satisfaction (3) & -1.025 & 0.329 & 9.689 & 1 & 0.002 & 0.359 & 0.188 & 0.684 \\
\hline Satisfaction (4) & -0.521 & 0.331 & 2.467 & 1 & 0.116 & 0.594 & 0.310 & 1.138 \\
\hline Distance from home to the nearest bus stop & 0.065 & 0.030 & 4.596 & 1 & 0.032 & 1.067 & 1.006 & 1.132 \\
\hline
\end{tabular}

of freedom, which means the used amount of data information when estimating statistics; $\operatorname{Exp}(\mathrm{B})$ means how much influence a variable has; $95 \%$ C.I for $\exp (B)$ is a confidence interval in which a parameter is included.

As a result of model estimation, age, which is a respondent characteristic variable, is removed because it presents no significant effect on the intention to use shared mobility. In other words, people do not have heterogeneous preferences and use intentions to shared mobility services for different age groups. Gender $(B=0.337$ and $p=0.029)$, mainly used transportation $(B=0.514$ and $p=0.009)$, possession of a car $(B=0.589$ and $p=0.008)$ or shared mobility $(B=0.738$ and $p=0.007 ; B=1.000$ and $p=0.009$, education $(B=0.608$ and $p=0.019)$, thoughts on shared mobility $(B=0.468$ and $p=0.027 ; B=1.179$ and $p=0.0003)$, satisfaction when using shared mobility ( $p=0.003)$, and distance to the nearest bus stop from home ( $B=0.065$ and $p=0.032$ ) are found to have significant effects. Especially, early adopters who have owned personal mobility devices $(B=1.000$ and $p=0.009)$ or already 
experienced shared services $(B=1.179$ and $p=0.0003)$ tend to think the future of shared mobility positively, as inferred from their highest $B$ values.

In the case of gender, since the coefficient has a positive value $(B=0.337)$, it can be determined that men are more willing to use shared services than women. According to the sign of the coefficient, people have a higher intention to use shared mobility in the following cases: using public transportation as their primary mode, owning a private car or extra vehicle to share, with higher education level than highschool graduation, experienced shared mobility at least once, having high satisfaction with past usage of shared mobility services, and suffering from long distance from home to nearest bus stop. It is because people who mainly use public transportation will get more benefits by mitigating the accessibility-related inconvenience, and these benefits should be greater if the current accessibility is low. Last, those who own an extra car have a high intention because this vehicle can be used for vehicle sharing.

These findings can be summarized by the following. First, the experience of using or owning personal mobility devices, introduced relatively recently compared to other transportation modes, has the most positive effect on the user intention. Thus, to promote shared mobility services to public, it is considerable to offer free or cheap opportunities to use such personal mobility devices. Second, we find which groups of people are more willing to use shared mobility services, so this knowledge can be used in two ways: we need to (i) focus on providing services to the groups with higher intentions in order to increase usage rate or (ii) advertise the services to the groups with less intentions to increase the potential population of future users. Last, if there is an inconvenience in using existing public transportation modes, there is a high possibility of becoming a potential user of shared mobility. It means that we need to first introduce shared mobility services on the sites associated with low accessibility to public transportation systems.

\section{Conclusions}

We conduct an online survey on shared mobility and analyze factors affecting user intention. Correlation and multicollinearity analyses are performed to reveal hidden relations among measures of intention to use and potentially influential factors. This study aims to better understand the intent of using shared mobility for practitioners, which can be developed into various policy proposals for future mobility dissemination. Additionally, factors affecting future intention to use shared mobility services are quantitatively analyzed through logistic regression, which can estimate willingness to use according to individual characteristics and usage conditions.

For the factors reflecting socio-demographic characteristics, the analysis results show that gender, possession of a car, and education have significant effects on future intention, while age has no significant effect. Furthermore, for the indicators related to past transportation usage, mainly used transportation modes, possession of a shared mobility device, past related experiences, satisfaction when using shared mobility, and distance from home to the nearest bus stop are shown to have significant effects on intention to use.

Among them, previous experience is identified as one of the most important factors determining its intention to use. It appears that people who have a shareable vehicle or have experienced shared transportation have a high intention to use such systems. This also can affect the satisfaction of users with the use of shared mobility. Thus, citizens who have been exposed to shared mobility services in the past lower hurdles to use in the future. Past experiences and satisfaction can reduce uncertainty and anxiety about the introduction of new modes. It will raise expectations for the introduction of shared mobility services. Therefore, it is important to establish a social environment that can easily deliver the benefits of shared mobility to potential users when introducing new mobility.

They also have a high intention to use when they have been mainly using public transit services, and this intention becomes higher as the distance from their home to the nearest bus stop increases. This is another notable finding in this study. The expectations of people's future use of shared mobility are closely tied to the location of existing public transport facilities. Thus, if the installation of public transport is sparse or the distance between transfers of public transport is far, introducing shared mobility can increase the likelihood of choosing this. Therefore, policymakers may need to consider introducing shared mobility services when a number of citizens are in such situations.

It is possible to propose a more effective policy if we consider the analysis results of the user intention and the existing usage of transportation modes at the same time. We find that existing shared mobility is mainly used for leisure/ tourism purposes rather than commuting. Therefore, in order to increase the utilization of shared mobility, introducing a service at a leisure or tourist complex may be considered. Moreover, it is found that vehicle-sharing mobility is more effective than personal mobility when trip distance is long. Likewise, personal mobility can be effectively introduced when the distance is relatively low, such as last-mile trips.

Coupled with the limitations of this study, we can consider some future research directions. This study focuses only on analyzing user intention in the future, assuming that shared mobility services are not currently settled and established. However, in many places in the world, services are in wide use, and their long-term usage and satisfaction statistics can be analyzed together to provide better services in the future. Moreover, to implement a shared mobility service in practice and suggest a policy, forecasting user intention and demand is not enough. A next step, a decisionmaking process, is needed to determine the scale and type of services. For this, both qualitative and quantitative methods can be adopted. As a qualitative method, it is possible to study cases of existing services based on the user demand, provided services, and user satisfaction. As a quantitative method, we can use an optimal decision-making framework to determine the most desirable scale and type of a newly introduced shared mobility service based on predicted 
demand and intentions. Last, in the current study, we identify which factors are actually influential, so it will be worth focusing on them for further detail. For example, education is shown to be significant in user intention. The group with a bachelor's degree or above, which accounts for $88.4 \%$ of respondents, can be subdivided into groups with Bachelor, Master, and Ph.D. degrees to see how much levels of higher education affect the awareness and use intention of various kinds of shared mobility services [37].

\section{Data Availability}

The data used to support the findings of this study is not publicly available according to the data security policy of Gyeonggi-do.

\section{Conflicts of Interest}

The authors declare no conflicts of interest.

\section{Acknowledgments}

This work was supported by the National Research Foundation of Korea (NRF) grant funded by the Ministry of Science, ICT and Future Planning (nos. 2020R1C1C1003296 and N01200545) and KAIST-KU joint Research Center, KAIST, South Korea.

\section{Supplementary Materials}

The supplementary description is as follows. Part 1: sample characteristics. Part 2: usage status of transportation and shared mobility service. Part 3: preference of shared mobility service. (Supplementary Materials)

\section{References}

[1] A. Millard-Ball, G. Murray, J. Ter Schure, C. Fox, and J. Burkhardt, "Car-sharing: where and how it succeeds," TCRP Report 104, Transit Cooperative Research Program (TCRP) Report, San Franciso, CA, USA, 2005.

[2] S. Shaheen, A. Cohen, and I. Zohdy, "Shared mobility: current practices and guiding principles," Report No. FHWA-HOP16-022, University of California, Berkeley, CA, USA, 2016.

[3] S. A. Shaheen and A. P. Cohen, "Growth in worldwide carsharing," Transportation Research Record: Journal of the Transportation Research Board, vol. 1992, no. 1, pp. 81-89, 2007.

[4] B. Cohen and J. Kietzmann, "Ride on! mobility business models for the sharing economy," Organization \& Environment, vol. 27, no. 3, pp. 279-296, 2015.

[5] P. DeMaio, "Bike-sharing: history, impacts, models of provision, and future," Journal of Public Transportation, vol. 12, no. 4, pp. 41-56, 2009.

[6] N. Davies, L. Blazejewski, and G. Sherriff, "The rise of micromobilities at tourism destinations," Journal of Tourism Futures, vol. 6, no. 3, p. 209, 2020.

[7] T. Kawaguchi, H. Murata, S. Fukushige, and H. Kobayashi, "Scenario analysis of car- and ride-sharing services based on life cycle simulation," Procedia CIRP, vol. 80, pp. 328-333, 2019.
[8] S. A. Shaheen, S. Guzman, and H. Zhang, "Bikesharing in Europe, the Americas, and Asia," Transportation Research Record: Journal of the Transportation Research Board, vol. 2143, no. 1, pp. 159-167, 2010.

[9] D. Efthymiou, C. Antoniou, and P. Waddell, "Factors affecting the adoption of vehicle sharing systems by young drivers," Transport Policy, vol. 29, pp. 64-73, 2013.

[10] G. Correia and J. M. Viegas, "Carpooling and carpool clubs: clarifying concepts and assessing value enhancement possibilities through a stated preference web survey in Lisbon, Portugal," Transportation Research Part A: Policy and Practice, vol. 45, no. 2, pp. 81-90, 2011.

[11] J. Firnkorn and M. Müller, "What will be the environmental effects of new free-floating car-sharing systems? the case of car2go in Ulm," Ecological Economics, vol. 70, no. 8, pp. 1519-1528, 2011.

[12] S. B. Kurth and T. C. Hood, "Car-pooling programs: solution to a problem?" Transportation Research Record, vol. 650, pp. 48-52, 1977.

[13] D. A. Prentice, D. T. Miller, and J. R. Lightdale, "Asymmetries in attachments to groups and to their members: distinguishing between common-identity and common-bond groups," Personality and Social Psychology Bulletin, vol. 20, no. 5, pp. 484-493, 1994.

[14] D. H. McKnight, L. L. Cummings, and N. L. Chervany, "Initial trust formation in new organizational relationships," Academy of Management Review, vol. 23, no. 3, pp. 473-490, 1998.

[15] S. Shaheen and C. Rodier, "Carsharing and carfree housing: predicted travel, emission, and economic benefits," in Proceedings of the 83rd Annual Meeting of the Transportation Research Board, Washington, DC, USA, January 2004.

[16] C. A. Rodier, "Review of the international modeling literature: transit, land use, and auto pricing strategies to reduce vehicle miles traveled and greenhouse gas emissions," in Proceedings of the Transportation Research Board (TRB) Annual Meeting, Washington, DC, USA, January 2009.

[17] G. J. Bruijn, S. P. Kremers, H. Schaalma, W. van Mechelen, and J. Brug, "Determinants of adolescent bicycle use for transportation and snacking behavior," Preventive Medicine, vol. 40 , pp. 658-667, 2005.

[18] E. Heinen and S. Handy, "Similarities in attitudes and norms and the effect on bicycle commuting: evidence from the bicycle cities Davis and Delft," International Journal of Sustainable Transportation, vol. 6, no. 5, pp. 257-281, 2012.

[19] H. Sherwin, K. Chatterjee, and J. Jain, "An exploration of the importance of social influence in the decision to start bicycling in England," Transportation Research Part A: Policy and Practice, vol. 68, pp. 32-45, 2014.

[20] M. A. Ahmed, A. M. Sadri, and M. Hadi, "Modeling social network influence on hurricane evacuation decision consistency and sharing capacity," Transportation Research Interdisciplinary Perspectives, vol. 7, Article ID 100180, 2020.

[21] M. M. Mortula, M. A. Ahmed, A. M. Sadri, T. Ali, I. Ahmad, and A. Idris, "Improving resiliency of water supply system in arid regions: integrating centrality and hydraulic vulnerability," Journal of Management in Engineering, vol. 36, no. 5, Article ID 5020011, 2020.

[22] S. A. Morshed, M. Arafat, M. Ashraf Ahmed, and R. Saha, "Discovering the commuters' assessments on disaster resilience of transportation infrastructure," in Proceedings of the International Conference on Transportation and Development 2020, pp. 23-34, Seattle, WA, USA, August 2020.

[23] Ö. Simsekoglu and C. A. Klöckner, "The role of psychological and socio-demographical factors for electric bike use in 
Norway," International Journal of Sustainable Transportation, vol. 13, no. 5, pp. 315-323, 2019.

[24] M. Matyas and M. Kamargianni, "The potential of mobility as a service bundles as a mobility management tool," Transportation, vol. 46, no. 5, pp. 1951-1968, 2018.

[25] C. Q. Ho, C. Mulley, and D. A. Hensher, "Public preferences for mobility as a service: insights from stated preference surveys," Transportation Research Part A: Policy and Practice, vol. 131, pp. 70-90, 2020.

[26] D. Dillman, J. D. Smyth, and M. Christian, Internet, Mail and Mixed-Mode Surveys: The Tailored Design Method, John Wiley \& Sons, Inc., Hoboken, NJ, USA, 3rd edition, 2009.

[27] Y. Kwon, S. Son, and K. Jang, "Evaluation of incentive policies for electric vehicles: an experimental study on Jeju Island," Transportation Research Part A: Policy and Practice, vol. 116, pp. 404-412, 2018.

[28] Y. Kwon, S. Son, and K. Jang, "User satisfaction with battery electric vehicles in South Korea," Transportation Research Part D: Transport and Environment, vol. 82, Article ID 102306, 2020.

[29] R. A. Likert, "Technique for the measurement of attitudes," Archiv für Psychologie (Frankf), vol. 55, p. 140, 1932.

[30] S. A. Shaheen, H. Zhang, E. Martin, and S. Guzman, "China's Hangzhou public bicycle," Transportation Research Record: Journal of the Transportation Research Board, vol. 2247, no. 1, p. 33, 2011.

[31] J. D. Cox and G. Pilcher, Thermochemistry of Organic and Organometallic Compounds, Academic Press, Cambridge, MA, USA, 1970.

[32] B. Ratner, "The correlation coefficient: its values range between $+1 /-1$, or do they?" Journal of Targeting, Measurement and Analysis for Marketing, vol. 17, no. 2, pp. 139-142, 2009.

[33] I. Lee, Easy Flow Regression Analysis, HanNaRae, Seoul, South Korea, 2014.

[34] D. Hosmer and S. Lemshow, Applied Logistic Regression, A Wiley-Interscience Publication, Hoboken, NJ, USA, 2nd edition, 2000.

[35] J. Cohen, P. Cohen, S. West, and L. S. Aiken, Applied Multiple Regression/Correlation Analysis for the Behavioural Sciences, Lawrence Erlbaum Associates, Manhwah, NJ, USA, 3rd edition, 2003.

[36] R. Christensen, Log-Linear Models and Logistic Regression, Springer-Verlag, Berlin, Germany, 1997.

[37] S. Shaheen, A. Cohen, N. Chan, and A. Bansal, "Sharing strategies: carsharing, shared micromobility (bikesharing and scooter sharing)," in Transportation Network Companies, Microtransit, and Other Innovative Mobility Modes, E. Deakin, Ed., ResearchGate, Boston, MA, USA, 2020. 